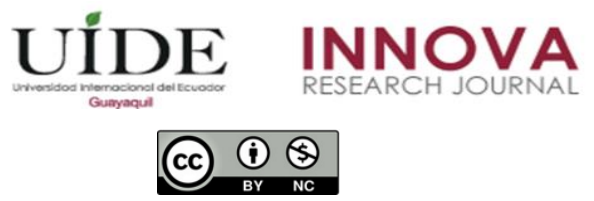

INNOVA Research Journal, ISSN 2477-9024

(Septiembre-Diciembre 2020). Vol. 5, No.3.2 pp. 272-294

DOI: https://doi.org/10.33890/innova.v5.n3.2.2020.1619

URL: http://revistas.uide.edu.ec/index.php/innova/index

Correo: innova@uide.edu.ec

\title{
Análisis de la influencia de la comunicación publicitaria a través de las redes sociales en los estudiantes de la Carrera de Comunicación social sede Guayaquil, horario nocturno
}

\section{Analysis of the influence of advertising communication through social networks on students at the Social Communication Career, Guayaquil campus, time night}

Betty Isabel Rodas Soto

(D) https://orcid.org/0000-0002-8906-470X

Universidad Politécnica Salesiana, Ecuador

Katerine Scarlett Ortega Muñoz

Universidad Politécnica Salesiana, Ecuador

Autor para correspondencia: brodas@ups.edu.ec; kortegam@est.ups.edu.ec

Fecha de recepción: 11 de octubre de 2020 - Fecha de aceptación: 23 de diciembre de 2020

\begin{abstract}
Resumen
La comunicación se exterioriza en un amplio campo de acción de forma multi- transdisciplinar, se evidencia en un contexto tecnológico y de consumos culturales. Una de las formas de comunicación es la publicidad conceptuada como persuasión y promoción de ideas, bienes o servicios, refleja una realidad sociocultural, que influye en la toma de decisiones de compra de los consumidores, evolucionando ante un entramado de mediaciones tecnológicas en la denominada sociedad de la información y del conocimiento adapta y cambia sus estrategias, en una época de narrativas y plataformas multimediales en la que de forma preferente las audiencias juveniles imponen y siguen tendencias, en espacios virtuales, transitando desde los clásicos MASS media a los medios digitales. Consecuentemente se considera para el análisis a las dos principales redes sociales con alcance juvenil: Facebook e Instagram. La selección muestral no probabilística, por conveniencia de 150 estudiantes de la carrera de comunicación social horario nocturno, de la UPS, Guayaquil da como resultado preliminar un grupo mayoritario de mujeres y un segmento comprendido entre 20 a 22 años que de acuerdo con los productos o servicios anunciados y el contenido generado se identifica lo cual crea participación, redefine hábitos e influye en una posible acción.
\end{abstract}

Palabras Clave: comunicación publicitaria; publicidad; Facebook; Instagram; redes sociales.

\begin{abstract}
Communication is externalized in a wide field of action in a multi-transdisciplinary way, it is evident in a technological context and cultural consumption. One of the forms of communication is advertising conceptualized as persuasion and promotion of ideas, goods or services, it reflects a socio-cultural reality, which influences the purchase decision-making of consumers, evolving in
\end{abstract}


the face of a network of technological mediations in the society of the information and knowledge society adapts and changes its strategies, in an era of narratives and multimedia platforms in the form of preference for youth audiences, imposing and following trends, in virtual spaces, moving from the classic MASS media to digital media . Consequently, the two main social networks with youth reach are considered for analysis: Facebook and Instagram. The non-probabilistic sample selection, for the convenience of 150 students of the career of social communication at night, at the UPS, Guayaquil, gives as a preliminary result a majority group of women and a segment between 20 to 22 years that according to the products or Advertised services and generating content is identified which creates participation, redefines habits and influences possible action.

Keywords: advertising communication; advertising; Facebook; Instagram; social networks.

\section{Introducción}

Las múltiples aristas que contempla la comunicación en el ámbito informativo, organizacional, social, político, personal entre otros, inciden en que se convierta en un campo de estudio extenso en el cual encuentra su espacio la publicidad como un tipo de comunicación persuasiva, no personal y parcializada a los intereses de un patrocinador. Junto con Wiese, Martínez y Botella (2020), se estima que la cotidianidad y el uso constante de los medios de comunicación tradicionales aunado al rol de las nuevas tecnologías y específicamente de las redes sociales, tornan al quehacer publicitario en una importante herramienta para comercializar las marcas o potencializarlas desde un ámbito moderno y cercano al consumidor.

Por otra parte, el consumismo implícito en una sociedad diferente, conceptuada por diversos teóricos como "sociedad de la Información y del conocimiento", 1 conmina al individuo a la interacción en nuevos espacios virtuales y físicos que de acuerdo con Rebollo-Bueno (2019), posibilitan la difusión de mensajes publicitarios en diferentes vehículos, canales y soportes, demostrando la omnipresencia de la publicidad.

Los mensajes publicitarios están inmersos en el entorno mediático, por tanto, al generar una influencia positiva en algunos casos y en otros un tanto ambiguo o contradictorio afecta al comportamiento de consumo del segmento de mercado pretendido, sin embargo, su atención y fidelidad resulta esquiva ante una amalgama de mensajes que saturan los medios tradicionales y acaparan cada vez más espacio y tiempo en las plataformas digitales.

Autores como Alonso (2017) y Ahmad Zareie, Amir Sheikhahmadi, Mahdi Jalilización (2020) consideran que la publicidad como una herramienta comunicacional orienta su accionar de acuerdo con los cambios actuales producto de la globalización, el desarrollo vertiginoso del internet y las nuevas tecnologías, por lo cual se recurre a estrategias como la publicidad BTL (Below the Line $)^{2}$ y OTL (On the line) $)^{3}$ importantes para la comunicación en redes sociales, las cuales, debido a sus características permiten contactar a los públicos en un ambiente

\footnotetext{
${ }^{1}$ Sociedad de la Información: es aquella en la cual las tecnologías facilitan la creación, distribución y manipulación de la información que juegan un papel esencial en las actividades sociales, culturales y económicas. Término por Manuel Castell

${ }^{2}$ BTL: Del inglés: below the line, término acuñado para referirse a las prácticas publicitarias no masivas.

${ }^{3}$ OTL: Del inglés: over the line, práctica publicitaria dirigida hacia un público amplio como el internet.
} 
distensionado de entretenimiento y evitar la evasión de los mensajes publicitarios. De este modo las redes sociales hacen que los posibles consumidores compren y prescriban un producto o servicio de una forma mucho más cercana a la convencional.

De acuerdo con los antecedentes planteados se aborda la investigación que refiere al análisis de la influencia de la comunicación publicitaria a través de las redes sociales, específicamente Facebook e Instagram con el propósito de identificar cómo influyen los mensajes publicitarios en un público objetivo joven para objeto de la investigación se toma como población a los estudiantes de la carrera de Comunicación Social de la Universidad Politécnica Salesiana (UPS) sede Guayaquil, horario nocturno para establecer el consumo mediático y la viabilidad que suponen estas plataformas en la promoción de ideas, bienes o servicios.

\section{La comunicación publicitaria en un entorno mediático.}

La publicidad metafóricamente actúa como espejo y esponja de la sociedad en la que está inmersa, junto con Santillán (2016) que concuerda con Saperas (2013) se considera que el avance tecnológico y la reinvención de los medios tradicionales está cambiando el orden social a un orden mediático, que afecta y favorece al desarrollo de nuevas formas de comunicación y la digitalización de las actividades económicas y sociales.

Por lo tanto, la publicidad se convierte en una importante herramienta comunicacional, según Vaca, Torres, Carpio, Jiménez y Barrazueta Ordóñez (2020) actúa sobre anunciantes, compradores y medios de comunicación de diversa manera desde un ámbito comercial, hedonístico y conductual incide en el proceso de construcción de la cultura de la sociedad contemporánea.

En este entramado de mediaciones tecnológicas, consumo y tendencias de mercado, la publicidad depende de la importante presencia de millones de usuarios en las redes sociales, específicamente en Facebook e Instagram, quienes constantemente interactúan en las diversas plataformas de información compartida, respecto a su utilidad se enmarca preponderantemente en los intercambios sociales:

La significación que se hace de las interacciones sociales que mantienen en Facebook, se ven influidas por aspectos que caracterizan la adolescencia, tales como la intensificación de la emocionalidad y cómo es manifestada en esta red social por las diferentes aplicaciones; la percepción de reconocimiento social a través de lo que las y los adolescentes comparten en la plataforma y como es percibido el "like"; el sentido de pertenencia y la presión social para tener una cuenta de Facebook; así como la oportunidad de establecer y mantener relaciones empáticas. (Ochoa Gutiérrez \& Uribe Alvarado, 2015, p. 23)

Las comunidades virtuales involucran la transmisión de expresiones, conformación de identidades ficticias en algunos casos con el afán de reconocimiento y sentido de pertenencia frente a otros usuarios, estas herramientas y bondades que ofrecen las redes sociales son aprovechadas para la mercadotecnia y la exposición publicitaria. "Con la aparición de las redes 
sociales, la comunicación de marketing cambió a un diálogo con los usuarios de Internet, y muchas estrategias de marketing evolucionaron" (Turban E., King D., Lee JK, Liang TP., Turban D.C. 2015 , p. 203).

Para autores como Velasco (2013) y Rebollo-Bueno (2019), las redes sociales constituyen estructuras y espacios en las que se comparten contenidos, información, opiniones, se representa un imaginario llevado de la realidad a la red e incluso se propicia una vocería ciudadana. Por su parte Tavares, Silva, Brito, Au-Yong-Oliveira (2018) consideran que la comunicación a través de las redes sociales acapara las preferencias de las audiencias.

En este sentido las plataformas de interacción social tales como: Facebook, Twitter, Instagram y YouTube mantienen el factor de la exposición constante en sus portales, propicio para desarrollar en ellas, acciones con herramientas creadas a partir de la necesidad presentada sean estas netamente de comunicación e incluso compra y venta de productos o servicios.

Diferentes empresas comprenden la utilidad de las redes sociales como plataformas de interacción social que posibilitan la presencia de marca e influyen en la posterior decisión de compra de un bien o servicio, de acuerdo con este planteamiento se considera que "el uso de las estrategias digitales, suponen una serie de cambios en la forma de crear campañas publicitarias para llegar a grupos objetivos dinámicos y participativos en la comunicación” (Novoa Montoya, 2019, p. 298), por tanto en líneas generales el target adolescente, joven y joven adulto manifiestan mayor participación y son un segmento atractivo para las empresas siendo necesario encontrar nuevas formas de comunicación para captar sus preferencias en la intención de compra.

\section{Públicos en redes sociales}

Las redes sociales son herramientas que permiten potencializar las marcas de bienes o servicios según la demanda generada por el grupo objetivo y de acuerdo con sus intereses, el empresario dirige sus esfuerzos en plataformas y comunidades virtuales. La consideración de las redes sociales como fuente de expresión es un aspecto importante para comprender a este tipo de plataformas que, según Méndiz, Victoria \& Arroyo (2013) constituyen un medio para que el sector juvenil exponga sus intereses, aficiones y se retroalimente con los contenidos expuestos a diferencia de otros grupos etarios. Domínguez \& Jarvio (2015) consideran importante la segmentación de los públicos en redes sociales mediante variables duras y blandas como sexo, nivel socioeconómico, gusto, preferencias entre otros:

A través de la selección de las respuestas modales se encontraron resultados interesantes que permiten diferenciar los gustos entre hombres y mujeres sobre el uso de las redes sociales. Es notorio que a las mujeres les gusta pertenecer a una red social para comunicarse con su familia, mientras que los varones usan este medio para comunicarse con compañeros y porque les parece interesante su uso y aprovechan o pasan el tiempo entretenidamente. (p. 25)

Los estudios de mercado aportan al conocimiento de los intereses que, a pesar de que podrían resultar muy generales no siempre pueden corresponder directamente a una realidad 
específica, sin embargo, sirve como punto de partida y entendimiento hacia los posibles gustos e intereses de los grupos a quienes se dirige una campaña. El autor Barrientos (2017) realiza un análisis del ingreso de las empresas a las redes sociales y cómo manejan estas nuevas tendencias las cuales considera positivas, pero requieren de trabajo y dedicación para obtener resultados, además aduce que:

Aunque las empresas pequeñas están ingresando tímidamente, lo importante es que lo están haciendo. Esto les permite mejorar su productividad y aumentar sus ventas, pues gracias a internet pueden ingresar a territorios a los que antes no era posible. Las empresas, sin distinción del sector económico, pueden impulsar sus negocios aprovechando lo que ofrece internet, de manera que refuercen su competitividad. Internet es un soporte de la globalización, y esta se encuentra dentro de las fronteras de un país. (p. 53)

Las prácticas publicitarias de cada empresa, según Pellicer (2015), deben ser éticas, pensadas en el desarrollo de la marca y el bienestar de los consumidores o espectadores, indica que:

Son muchas las razones que avalan la necesidad de una publicidad ética, que beneficiaría a los cuatro protagonistas del proceso publicitario: los anunciantes, los publicistas, el producto y los consumidores. Una publicidad ética permitiría anunciantes con más credibilidad, publicistas reconocidos socialmente, productos que satisfacen a los consumidores y consumidores fieles a la marca y satisfechos. (p. 306)

Desde esta perspectiva la ética ofrece el marco axiológico, a la publicidad en redes permitiendo una relación a largo plazo con el consumidor para fidelizar, posicionar y efectivizar la venta. La publicidad ha encontrado en las redes sociales un nuevo espacio en el que las prácticas de mercadotecnia toman protagonismo en conjunto con las herramientas que ofrecen las plataformas tales como Facebook e Instagram, las cuales han logrado abarcar a diversos públicos y generar ingresos importantes para las empresas ofertantes.

De acuerdo con el estudio realizado por Marcelino (2015) acerca de la migración del sector juvenil de la red social Tuenti, con mayor presencia en España, a la red social Facebook debido a las nuevas herramientas que esta ofrecía, así como el análisis de la nueva migración y surgimiento de usuarios provenientes de Facebook hacia Instagram, considera que este tipo de cambios surge a partir de las necesidades de expresión por parte de los jóvenes en conjunto con los afanes de actualizarse constantemente, puesto que Instagram ofrece herramientas mejoradas hacia lo audiovisual tales como fotografías con filtros, compartir historias inmediatas y la posibilidad de exponer productos o servicios que a este sector le interesan.

Según un análisis realizado por Himelboim y Golan (2019) apunta que la participación en redes aunado a la estructura generada para la viralidad de contenidos en la web permite dividir y catalogar cada grupo de consumidores, desde los más influyentes hasta los menos influyentes. Referente a esta temática, Valerio, et. al. (2015) considera que los administradores de páginas en redes sociales tales como Facebook deben estar atentos ante los cambios, necesidades y sugerencias que la audiencia indica, caso contrario podrían perder presencia de marca y disminuir las ventas. 
El reto ante los avances vertiginosos de las tecnologías y la comunicación consiste en establecer formas de captar la atención con publicaciones constantes acerca de temáticas actuales en las que puedan sentirse identificados para acercar el producto, servicio o la propia marca al potencial consumidor. La recursividad, un buen uso de estrategias comunicacionales y una buena segmentación son factores claves para que una campaña en redes sociales logre resultados óptimos ajustados a la inversión costo-beneficio.

\section{Redes sociales y publicidad: Caso Facebook e Instagram}

Los creativos publicitarios emplean a las redes sociales para contactar a nuevos públicos que desde un consumo hedónico y de placer no solo se orientan al entretenimiento sino también a la actualidad e información para Rubalcava de León (2019) manifiesta que en el uso de redes sociales con fines publicitarios se crea una conciencia de marca al ofrecer mediante ilustraciones, audiovisuales y una variedad de contenido, novedad y diferenciación a través de ventajas competitivas de los productos o servicios anunciados, pero a la vez implica aspectos negativos tales como la intromisión a las actividades rutinarias relacionadas con el entretenimiento y el uso de la Web.

En este orden de ideas, Serrano-Malebrán y Arenas-Gaitán (2019) manifiestan que el factor personalización (recopilación de datos e información privada de los clientes) podrían afectar el comportamiento de compra al crear cierta desconfianza ante la privacidad vulnerada con el desarrollo de mensajes publicitarios con un contenido directo.

Desde este contexto las estrategias aplicadas en la red social de Facebook e Instagram han consentido cambios sustanciales en la forma de pautar y contactar al target de una marca, los avisos y publicaciones crecen tanto como la cantidad de internautas, de este modo "(...) la red social de fotografías de Mark Zuckerberg ahora aumentará su cantidad de anuncios en las historias" (La voz, 2019, párr. 2) además en la publicación antes citada se puntualiza que cerca de 500 millones de usuarios al día usan las historias de Instagram por lo cual constituiría una potencial mina de oro para Facebook.

Las oportunidades que ofrecen Facebook e Instagram respecto a la presencia, establecimiento y constante crecimiento de las marcas generan la posibilidad de espacios para la comercialización de productos y servicios de todo tipo en el mundo entero mediante estrategias de e-commerce ${ }^{4}$ involucrando a público diverso emprendedores y usuarios particulares con cuentas en dichas redes sociales así como a pequeñas, medianas o grandes empresas que además trabajan con otras plataformas.

En cuanto a los costos y paquetes de publicidad en redes sociales pueden variar según la necesidad del usuario o empresas anunciantes, específicamente en la red social Facebook es posible promocionar un aviso por un valor aproximado de $\$ 3$ en delante de acuerdo con datos de la misma plataforma Facebook al año 2019, esto es correlativo según el alcance que se desee, el

\footnotetext{
${ }^{4}$ E-commerce: consiste en el marketing y venta de productos o servicios a través de Internet. En definitiva.
} 
público según rango de edad, sexo, localidad y otros factores que se encuentran en las herramientas de los avisos de la red social Facebook.

Para Zhikona, Willie \& Liezel (2019) en 2005, cuando Facebook lanzó su primer plan publicitario, se ha logrado un avance significativo ofreciendo una opción de publicidad razonablemente de bajo costo y la oportunidad de llegar a un público y cuando los anuncios sean lo suficientemente atractivos. En el caso de la red social Instagram, perteneciente a la empresa Facebook, el asunto de los anuncios no varía del todo, más bien la cuestión del modo en el cual se llevan a cabo sí, es decir, existen historias, publicaciones, avisos entre historias y la configuración depende del alcance y requerimientos del usuario o la empresa al igual que la anterior red mencionada.

La diferencia radica en las características de los públicos hacia quienes se dirige la publicidad, según estudios propios de Facebook e Instagram (2018), sus usuarios varían en rango de edad según la interacción, generalmente los sujetos entre 13 a 30 años son los que recurren con mayor frecuencia a Instagram y un rango estimado de sujetos entre 12 a 40 años tienen una cuenta en Facebook, lo que invita a las empresas a abarcar estrategias diversas según sus intereses.

Autores como Fondevila-Gascón, Polo-López, Rom-Rodríguez y Mir-Bernal (2020) coinciden en que las redes sociales como tal son una estrategia publicitaria y a su vez sostienen que las herramientas a utilizar refiriéndose al campo virtual sufren un sin número de actualizaciones por lo que es necesario cambios constantes para un mejor control del consumidor. Esto ha provocado, según Alonso (2017) una nueva tendencia respecto a la mercadotecnia, en cuanto a la creación de estrategias efectivas vinculada a la identificación con referentes o personajes populares que representan a una marca o empresa, permitiendo un acercamiento más directo a los intereses del usuario además considera que:

La nueva tendencia del marketing, que está despertando interés en el mundo empresarial es el personal branding, entendida como la disciplina que busca identificar, potenciar y comunicar los talentos, aptitudes y habilidades de cualquier profesional para buscar su diferenciación de entre su competencia y maximizar así su rendimiento y eficiencia profesional, y por ende también mejorar su satisfacción y felicidad personal. (p. 6)

Al respecto, autores como Ahmad Zareie, Amir Sheikhahmadi, Mahdi Jalilización et. al. (2020) reconocen que en la actualidad las empresas buscan representar sus productos icónicamente encarnando sus atributos y se convierten en prescriptores de la marca generando a su vez un buzz marketing para que el segmento de mercado pretendido no solo compre sino además recomiende el producto o servicio. En definitiva, las redes sociales, su evolución y diversas temáticas orientadas a la publicidad resultan de interés científico, académico y por ende influyen en la cotidianidad de todos quienes las consumen, debido a que su impacto afecta de formas diversas a todos sectores de la sociedad. 


\section{Metodología}

El presente estudio se alinea a una investigación cuali-cuantitativa de tipo descriptivo, para autores como Hernández Sampieri, Fernández Collado y Baptista (2014) el conocimiento sobre el problema de investigación y la revisión de literatura determina la selección de la investigación descriptiva frente a otras, por otra parte, se destaca que al recurrir a una metodología mixta se posibilita la recolección de datos cualitativo y cuantitativos a través de diferentes técnicas y procedimientos de investigación, según lo señalado por la autora Pole (2009) la metodología mixta tiene un acercamiento a lo cualitativo:

Los investigadores que utilizan metodologías mixtas tienden a acercarse más con perspectivas cualitativas, incluyendo la creencia de que existen múltiples realidades que dependen del individuo, pero responden a sus preguntas al combinar métodos cuantitativos y cualitativos de diversas maneras, en orden paralelo, concurrente o secuencial (p. 39)

La misma autora reflexiona sobre el quehacer de los investigadores de las ciencias sociales y de la conducta que recurren indistintamente a lo cuantitativo y cualitativo, sin embargo, se identifica una tendencia a utilizar los métodos mixtos al combinar enfoques se logra contrastar, complementar y explorar distintos aspectos de la investigación.

Paralelamente, a la metodología detallada se subraya el uso de la técnica de revisión documental que permite fundamentar teóricamente el objeto de estudio de la investigación o desarrollar un estado del arte que a criterio de varios autores consiste en : “ ...investigar desde la óptica de "ir tras las huellas" del campo de conocimiento que se pretende ahondar, permitiendo determinar cómo ha sido tratado éste y cuáles son las tendencias" (Rojas, 2007; Caro Gutiérrez et al., 2005 citado en Barbosa, 2013 , p.89).

Partiendo de esta contextualización que justifica el enfoque metodológico se desarrolla en la presente investigación la revisión bibliográfica de estudios previos y autores afines a la comunicación publicitaria y publicidad en redes sociales que permitan sustentar académicamente y de forma científica el avance del análisis acerca de la temática. De igual forma se procede a la aplicación de la encuesta empleando como instrumento el cuestionario que a criterio de Hernández Sampieri, Fernández Collado y Baptista (2014) permite la recolección de datos de una forma sistemática y estructurada. Los sujetos de estudio son los estudiantes universitarios de la carrera de comunicación social horario nocturno de la UPS sede Guayaquil.

La selección muestral obedece al criterio muestreo no probabilístico y por conveniencia, para autores como Otzen y Manterola (2017) este tipo de técnica requiere de características tales como experticia, accesibilidad y proximidad para el investigador. Por tanto, la muestra corresponde a 150 de la población puntualizada que, debido a su formación académica, a pesar de su conocimiento diverso y disperso sobre el tema de publicidad, así como el uso recurrente de las redes sociales resulta conveniente para contrastar datos y para los fines de la investigación.

Como otro instrumento de investigación se recurre a la entrevista semiestructurada, Junto con Díaz (2013) se considera que esta técnica cualitativa consiste en un guion de preguntas para 
la interlocución entre el investigador y el sujeto del cual se pretende recabar cierta información desde la experticia en este caso de profesionales, involucrados en el quehacer publicitario y docentes del área para obtener un criterio fiable.

Finalmente, para comprender la temática desde la complejidad y la experiencia de profesionales, se desarrollan entrevistas con personajes que se encuentren involucrados de una $\mathrm{u}$ otra forma en la temática de la comunicación, publicidad y redes sociales con el objetivo de sustentar bajo lo empírico.

\section{Resultados}

Las variables edad y el sexo, son dos indicadores importantes para analizar el comportamiento de consumo y uso de redes sociales. El rango de edad que prevalece está comprendido entre $20-22$ años con el $56 \%$. En cuanto a la identificación por sexo, el $57 \%$ corresponde al público femenino y el $43 \%$ para el masculino. Se considera la escala de valoración totalmente de acuerdo y de acuerdo para determinar la ponderación a favor de un enunciado.

De acuerdo con los datos recabados el $26 \%$ de las encuestas realizadas al género femenino y el $23 \%$ público masculino manifiesta que su decisión de compra está relacionada con la información dada en redes sociales.

\section{Figura 1}

Decisión de compra respecto a una red social.

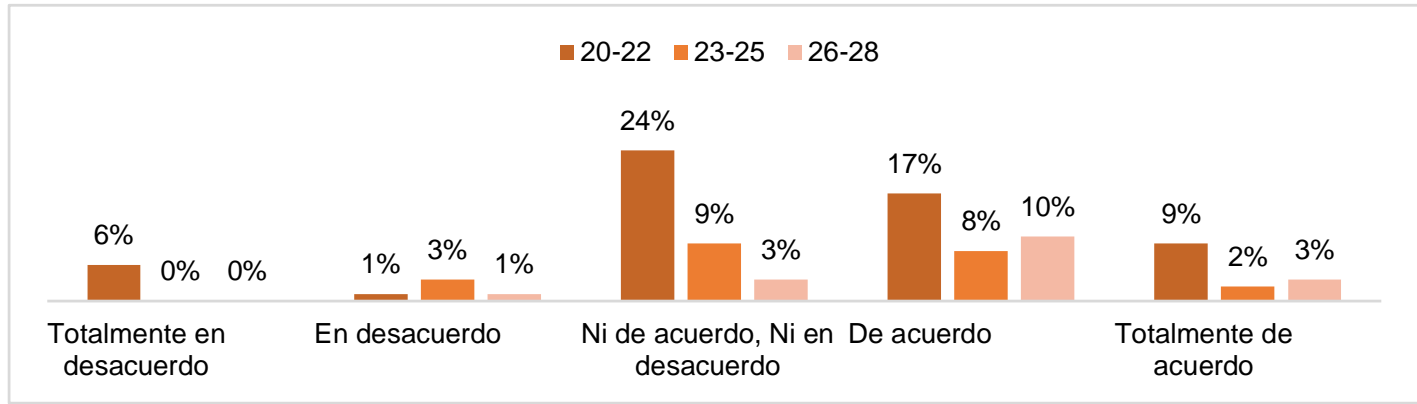

\section{Figura 2}

Decisión de compra respecto a una red social

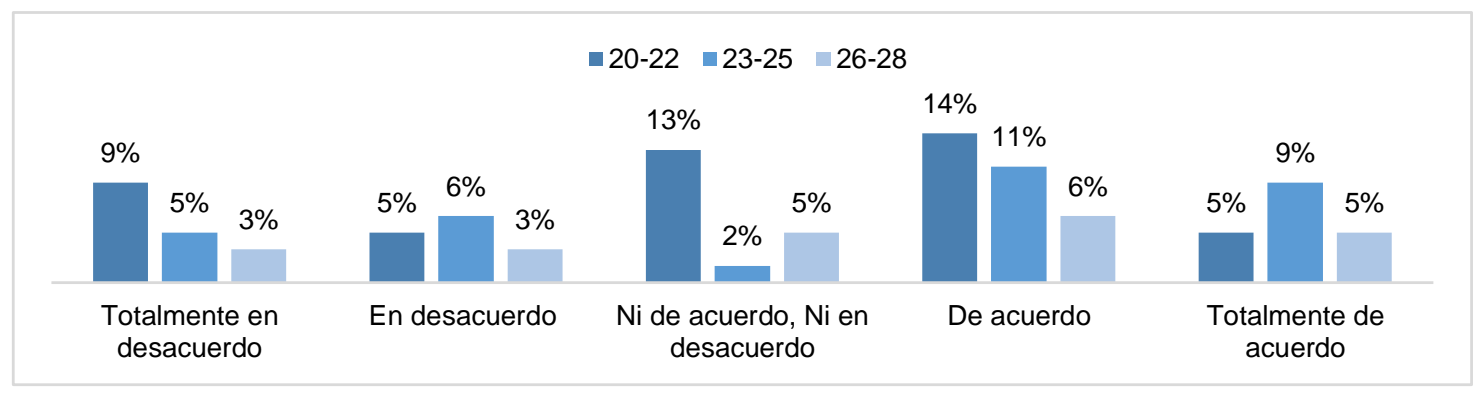


Con relación al planteamiento sobre el uso de la publicidad en redes sociales frente a los medios tradicionales, el público femenino está a favor de los medios digitales frente a los tradicionales con un $23 \%$. En tanto que la audiencia masculina, con un $18 \%$ declara una postura a favor de los medios digitales.

\section{Figura 3}

La publicidad en redes sociales frente a los medios tradicionales.

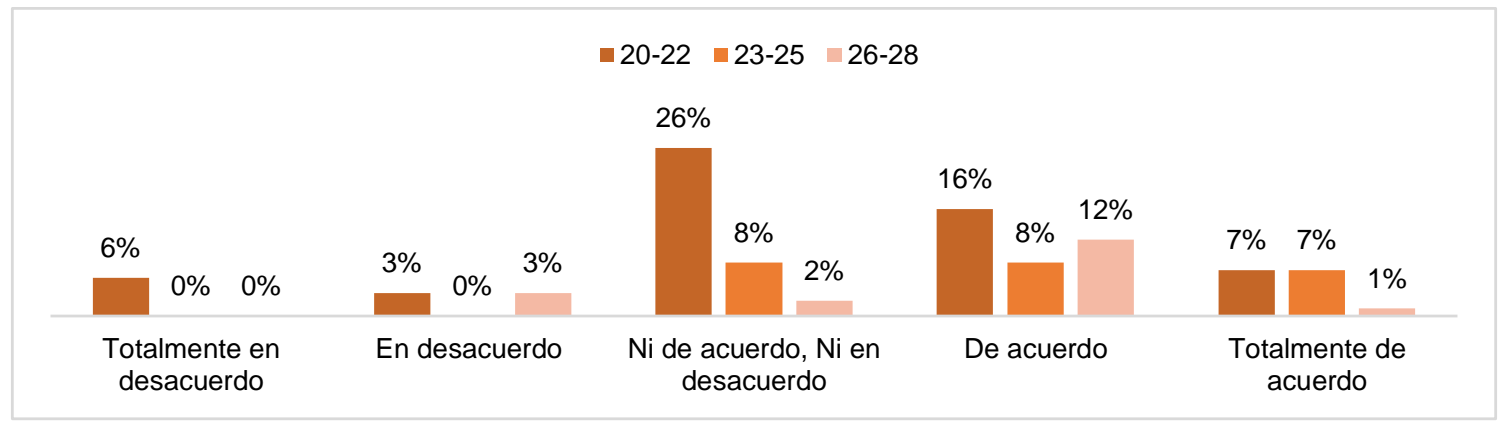

\section{Figura 4}

La publicidad en redes sociales frente a los medios tradicionales.

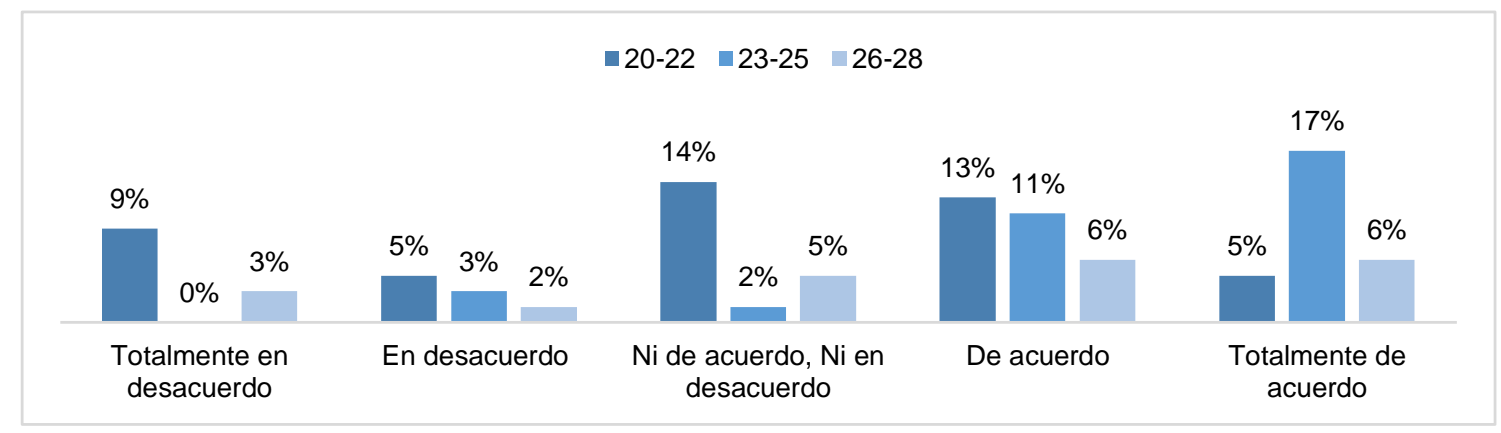

Las redes sociales son consideradas como el medio idóneo para difundir mensajes publicitarios, concuerdan con este enunciado el $46 \%$ y el $35 \%$ del segmento femenino y masculino respectivamente. De este modo, es apreciada favorablemente para la información publicitaria, la red social Instagram con un 46\% y Facebook con el $28 \%$ en el segmento femenino; el segmento masculino prefiere Instagram con el 28\% y Facebook con el $23 \%$. 


\section{Figura 5}

Las redes sociales como medio para la difusión de mensajes publicitarios.

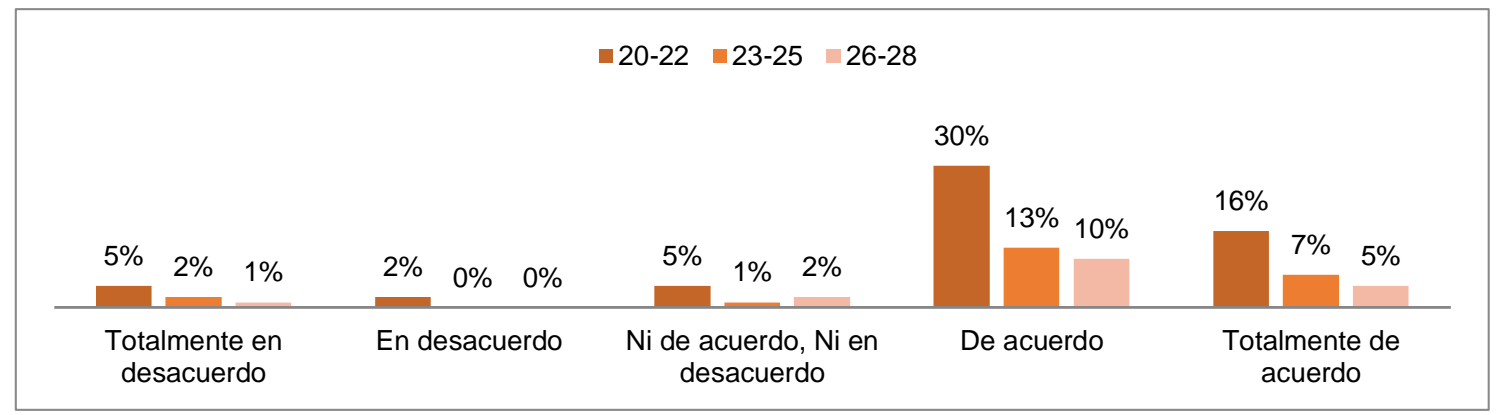

\section{Figura 6}

\section{Las redes sociales como medio para la difusión de mensajes publicitarios.}

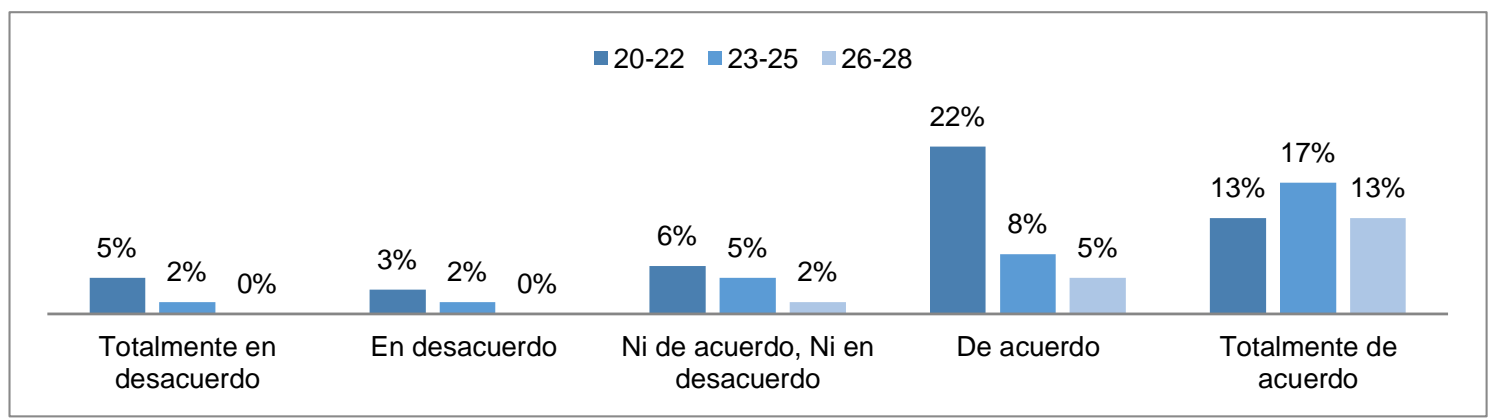

\section{Figura 7}

Jóvenes prefieren Facebook para la información.

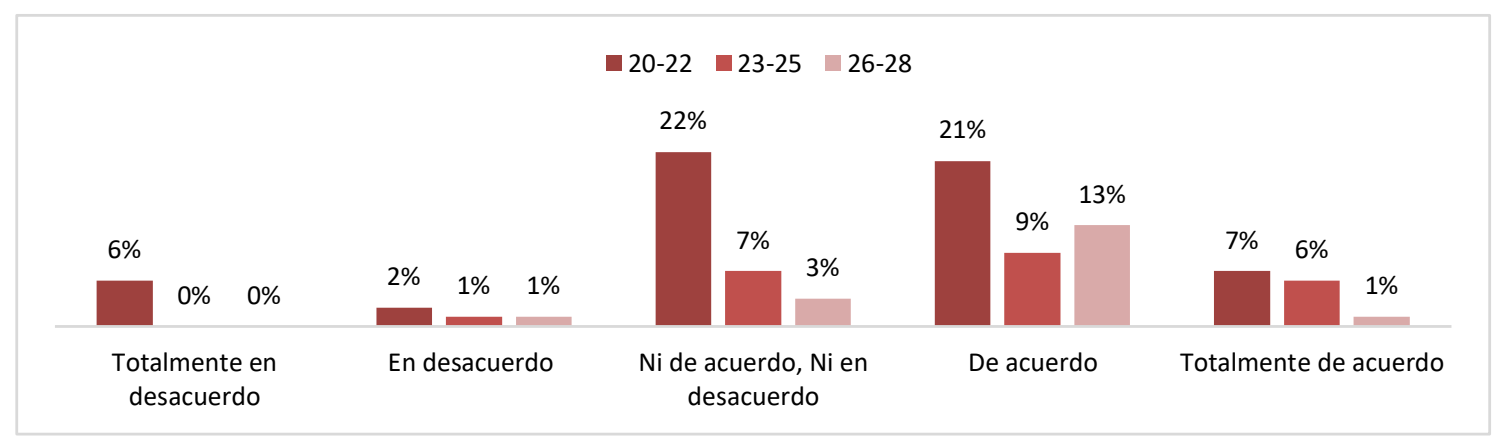




\section{Figura 8}

Jóvenes prefieren Facebook para la información.

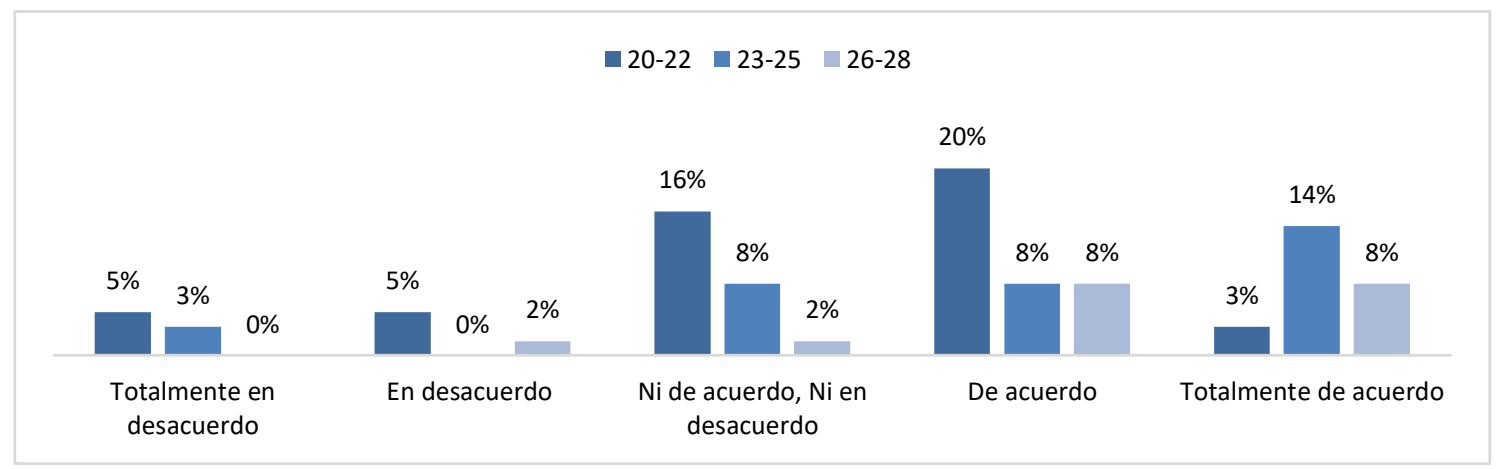

\section{Figura 9}

Jóvenes prefieren Instagram para la información.

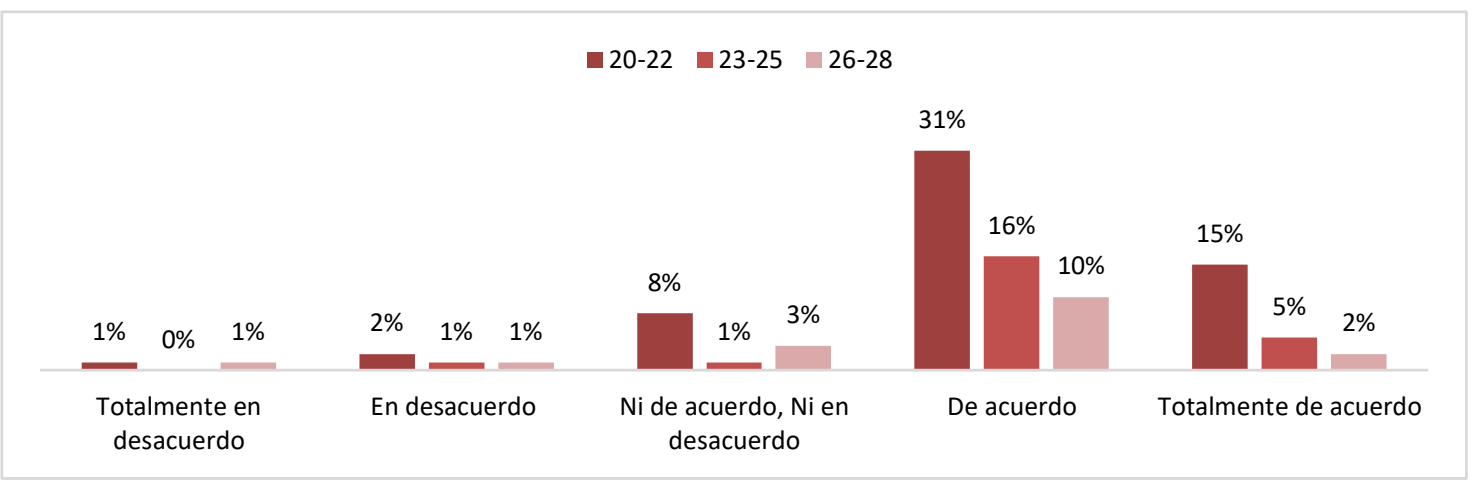

\section{Figura 10}

Jóvenes prefieren Instagram para la información.

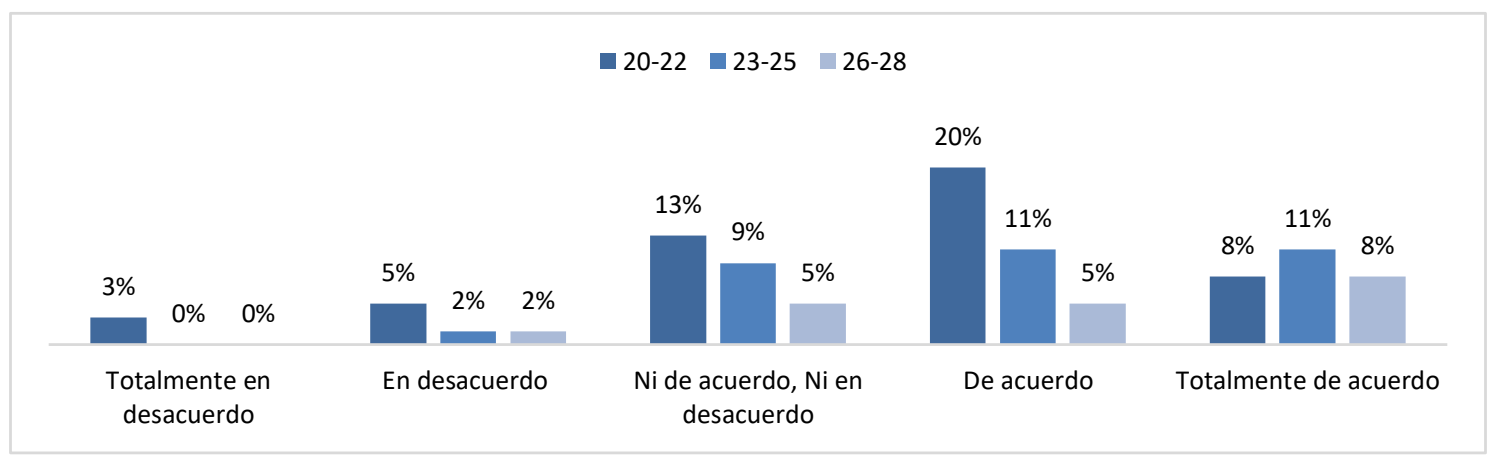


Navegar en redes sociales forma parte de la cotidianidad de jóvenes y adolescentes, por lo cual, el estar presente en las redes sociales posibilita el consumo de determinadas marcas el 50\% del segmento femenino y el $28 \%$, del público masculino comparten este criterio.

\section{Figura 11}

Estar presente en las redes posibilita el consumo de determinadas marcas.

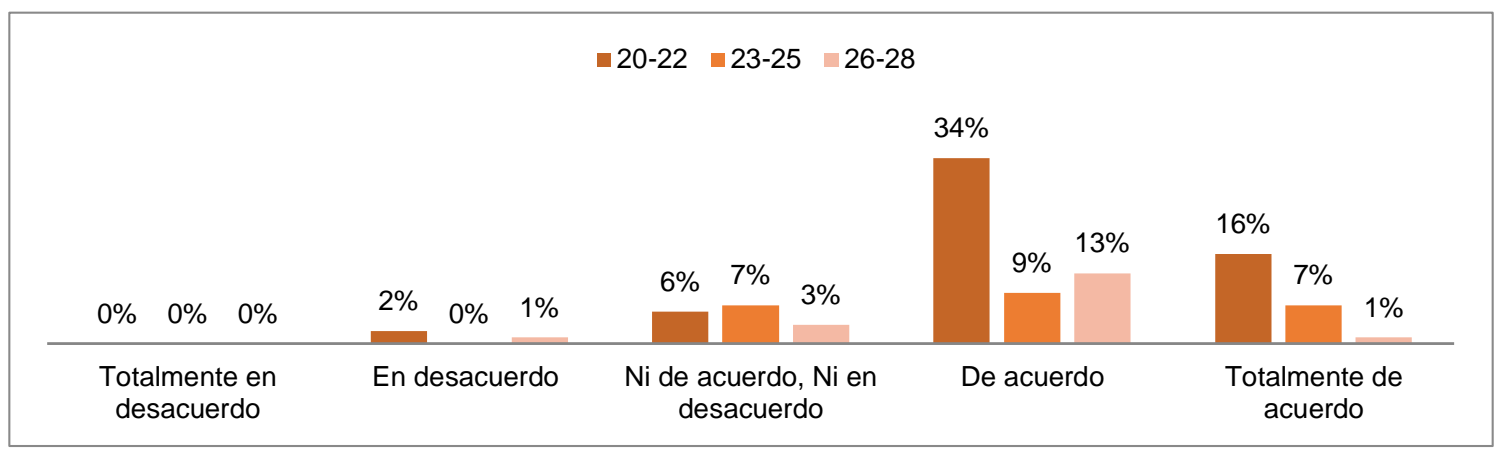

\section{Figura 12}

Estar presente en las redes posibilita el consumo de determinadas marcas.

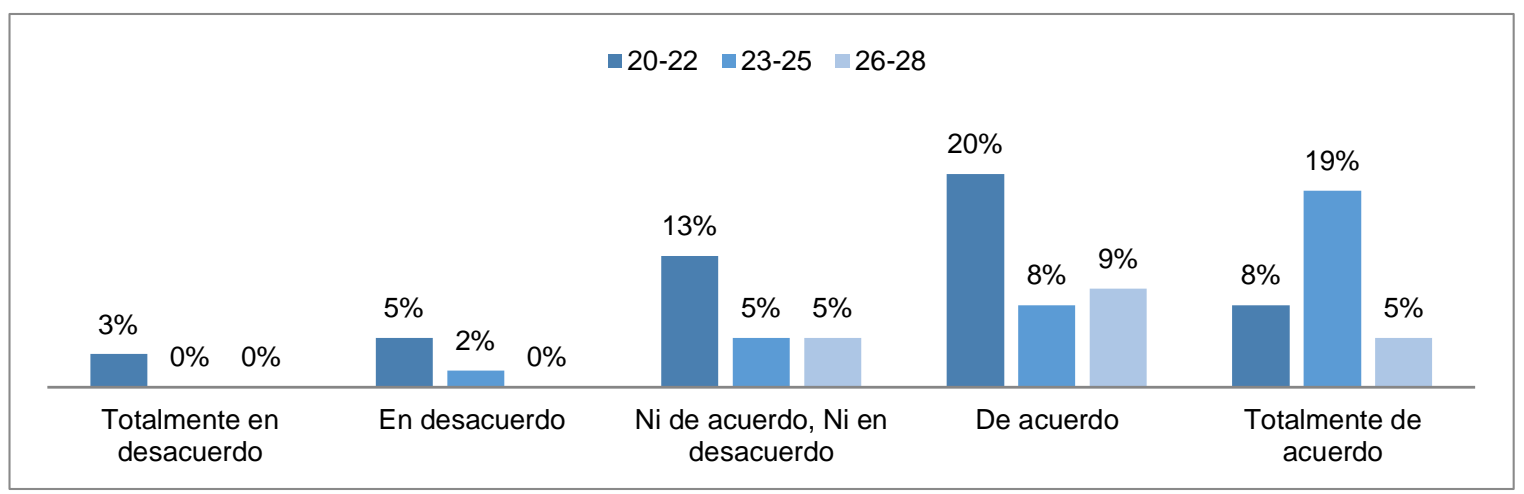

Comunicar para persuadir requiere del uso de diversas estrategias, para los encuestados recurrir a la prescripción publicitaria de Influencers, puede resultar efectiva el $27 \%$ del segmento femenino opta por este tipo de mecanismo, en tanto que el segmento masculino refleja sólo un $16 \%$, este mismo target elige el uso de videos cortos en un $19 \%$. 


\section{Figura 13}

Tipo de estrategias publicitarias más efectivas en redes sociales

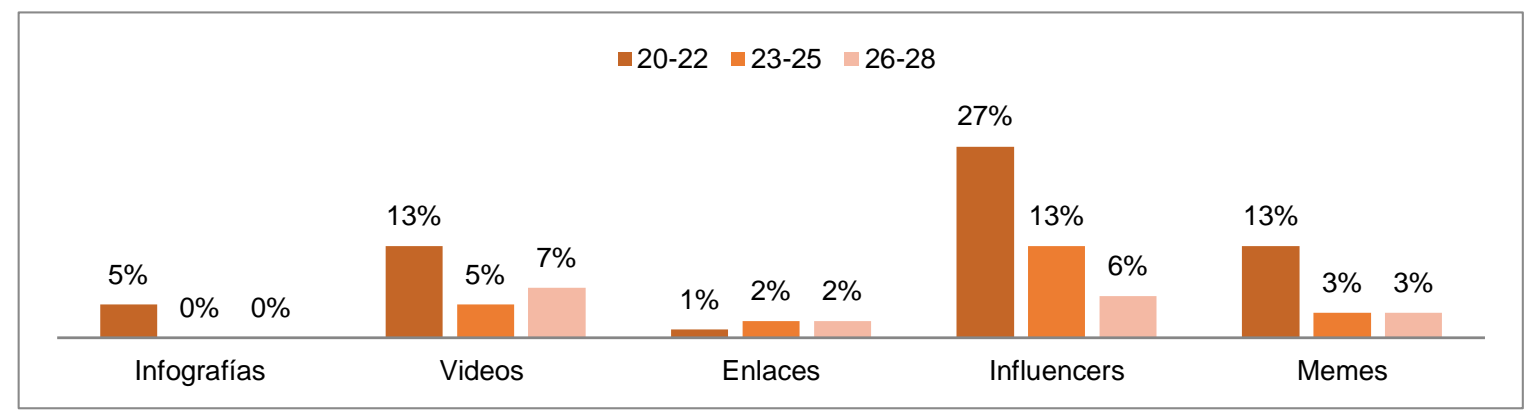

\section{Figura 14}

Tipo de estrategias publicitarias más efectivas en redes sociales

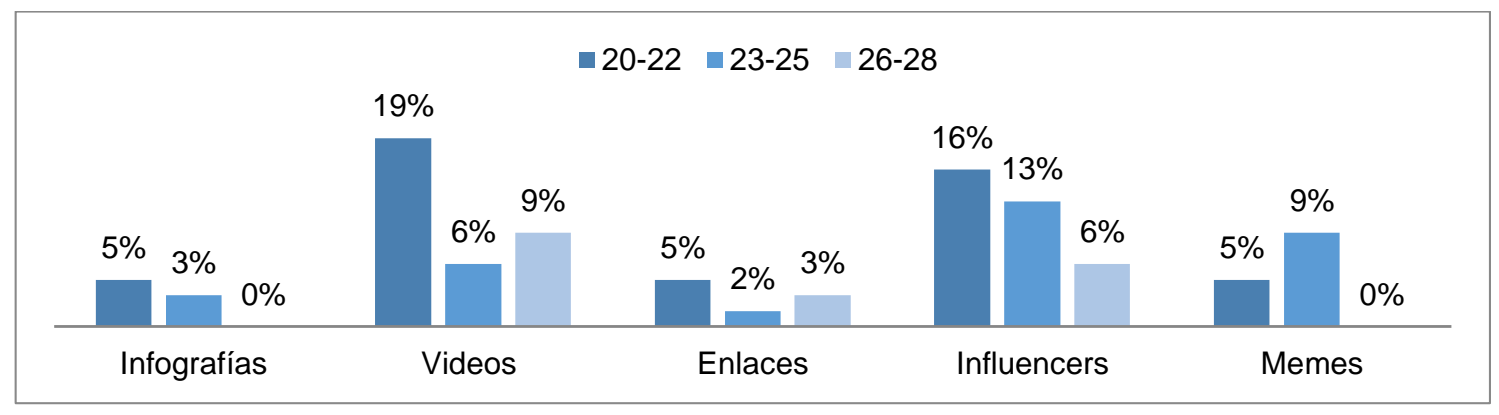

La presencia de marcas y empresas en redes sociales, son catalogadas de importancia el $48 \%$ y el $33 \%$ del target femenino y masculino en su respectivo orden, tienen tal apreciación. Se evidencia que las comunidades virtuales tienen acogida en el segmento juvenil, de acuerdo con la encuesta, la red social Instagram tiene mayor presencia y usabilidad en las estudiantes con el $50 \%$ en tanto que Facebook alcanza el 34\%. El público masculino otorga mayor relevancia a Instagram con un 19\% y Facebook con solo un 5\%.

\section{Figura 15}

Marcas y empresas presentes en redes sociales

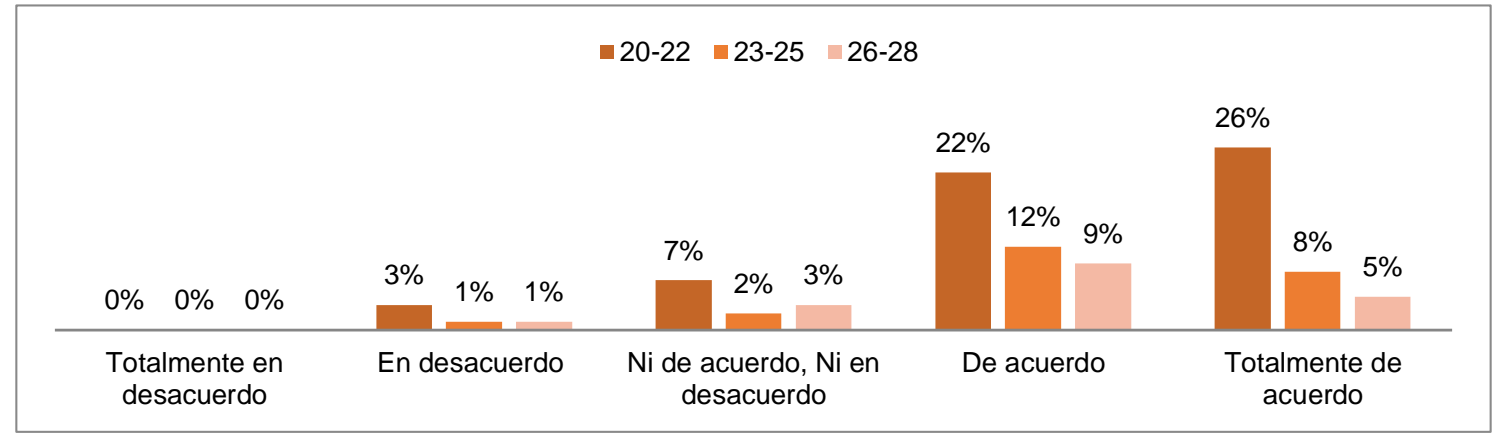




\section{Figura 16}

Marcas y empresas presentes en redes sociales

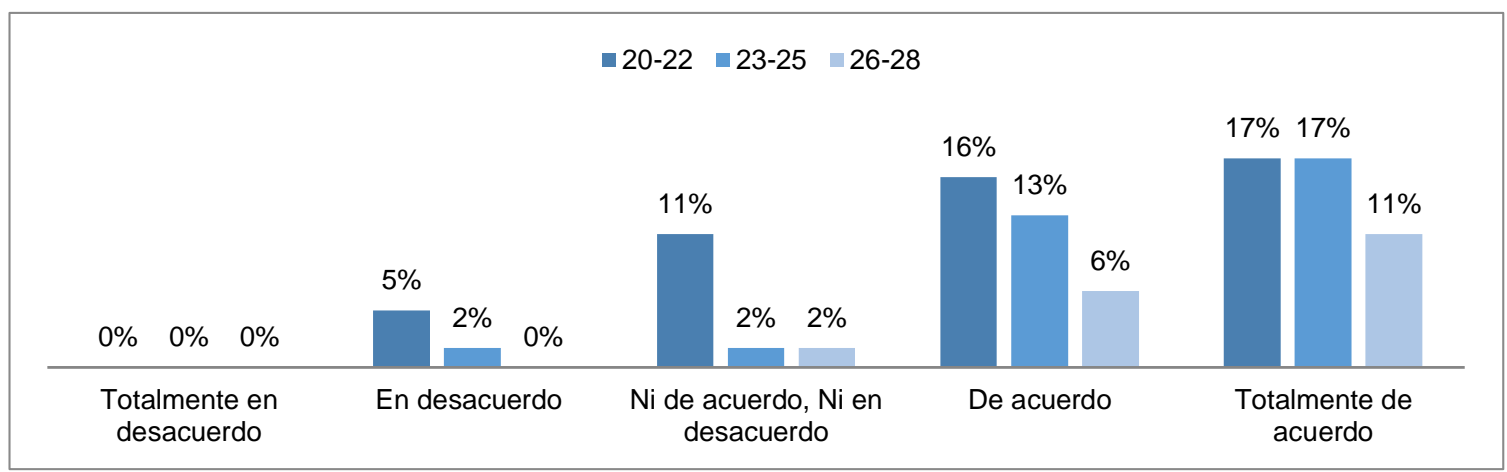

\section{Figura 17}

Redes sociales con mayor presencia

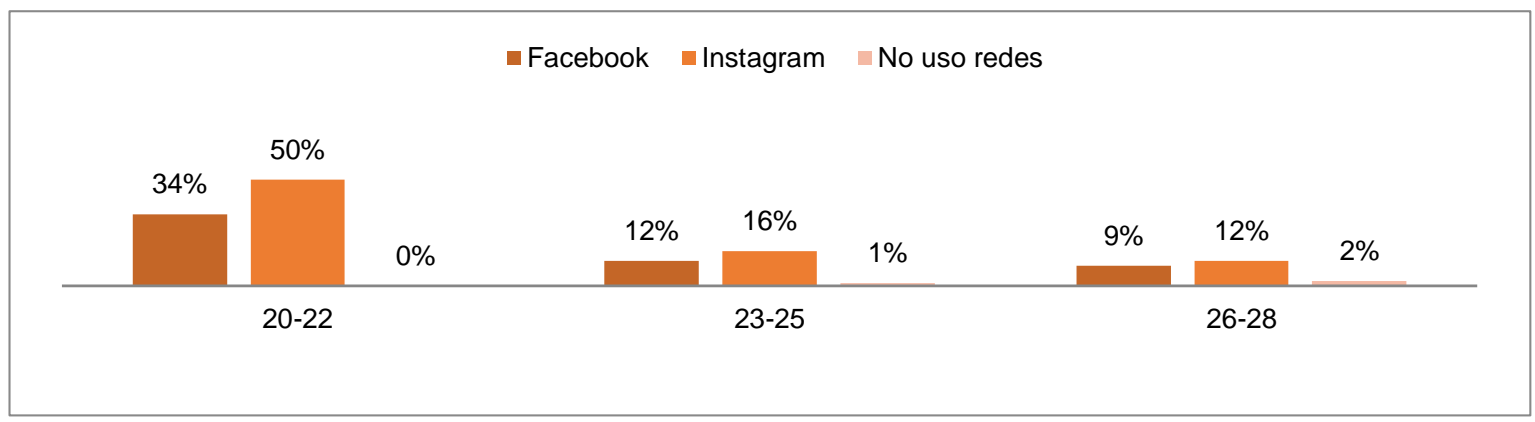

\section{Figura 18}

Redes sociales con mayor presencia

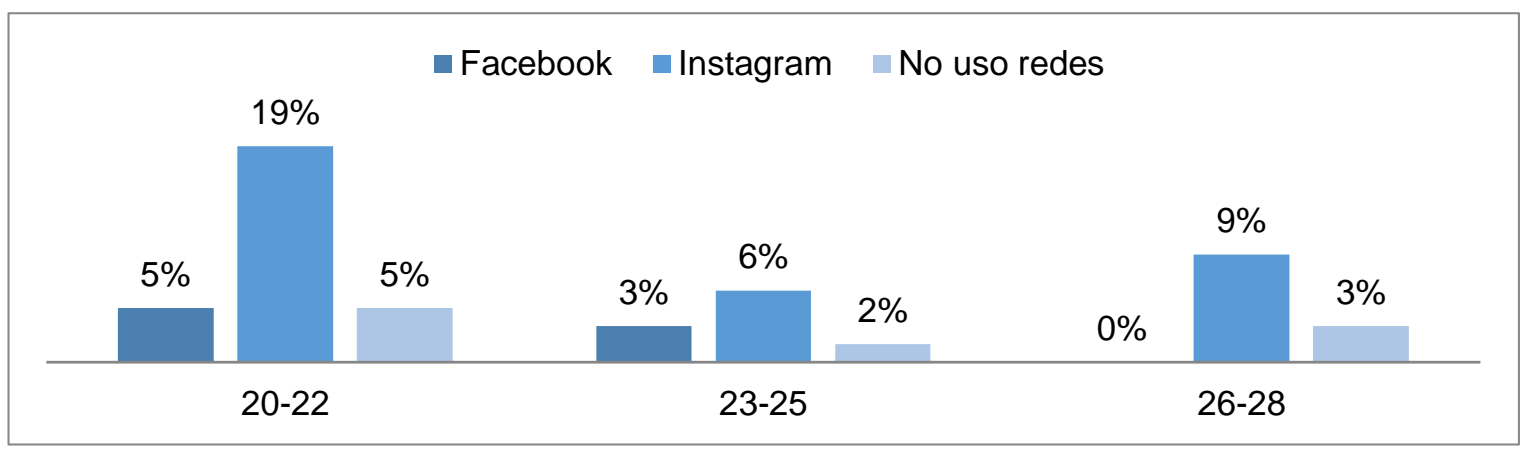


En lo concerniente al uso de las redes sociales para el entretenimiento, el 37\% del segmento femenino y $28 \%$ del segmento masculino encuestado se orientan hacia este fin. Se resalta en este sentido que, para anunciar una marca, es recomendable unirse a las actividades de ocio y esparcimiento del potencial comprador.

\section{Figura 19}

\section{Uso de las redes sociales}

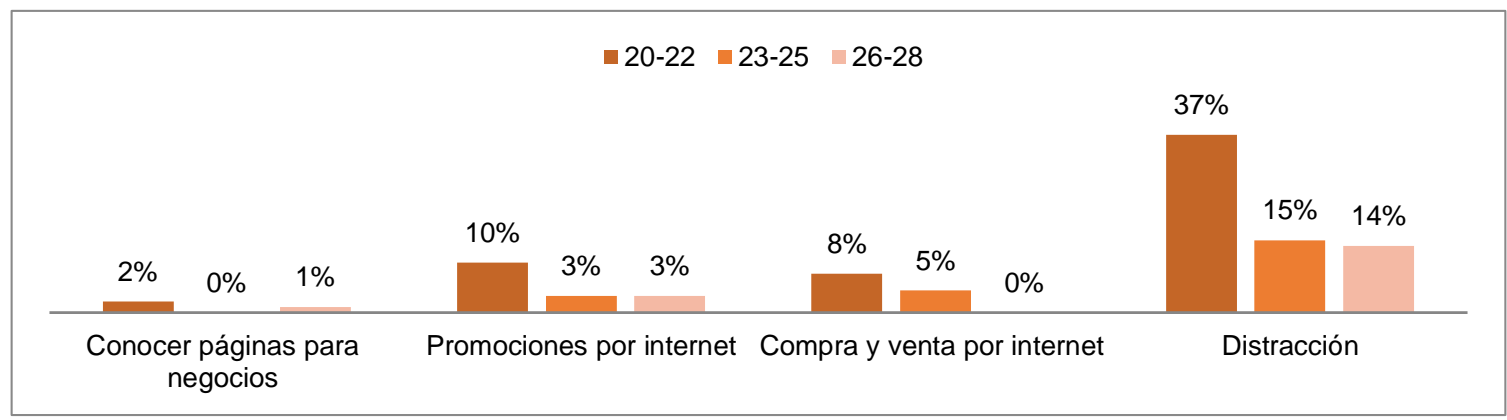

\section{Figura 20}

Uso de las redes sociales

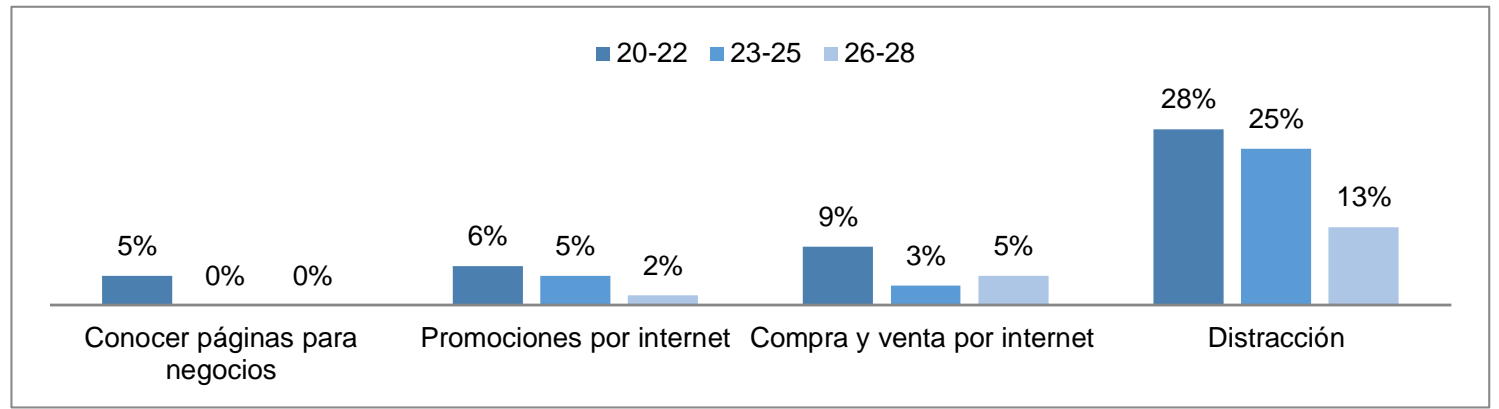

Referente al tipo de publicaciones que captan la atención en las campañas publicitarias digitales se encuentran las fotografías con el $28 \%$, videos cortos $16 \%$ en el público femenino; mientras que el público masculino prefiere las fotografías e infografías con similar porcentaje, $14 \%$.

\section{Figura 21}

Tipo de publicaciones publicitarias que captan la atención

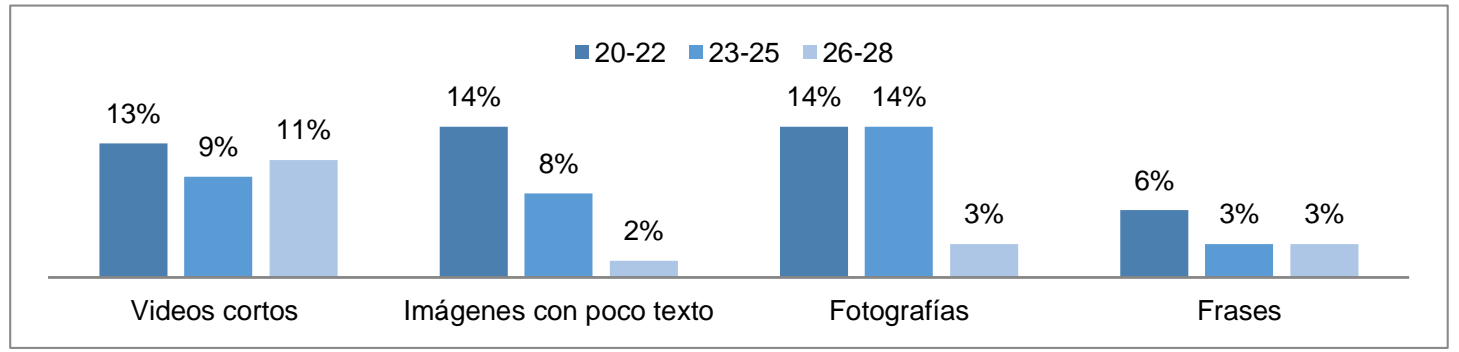




\section{Figura 22}

Tipo de publicaciones publicitarias que captan la atención

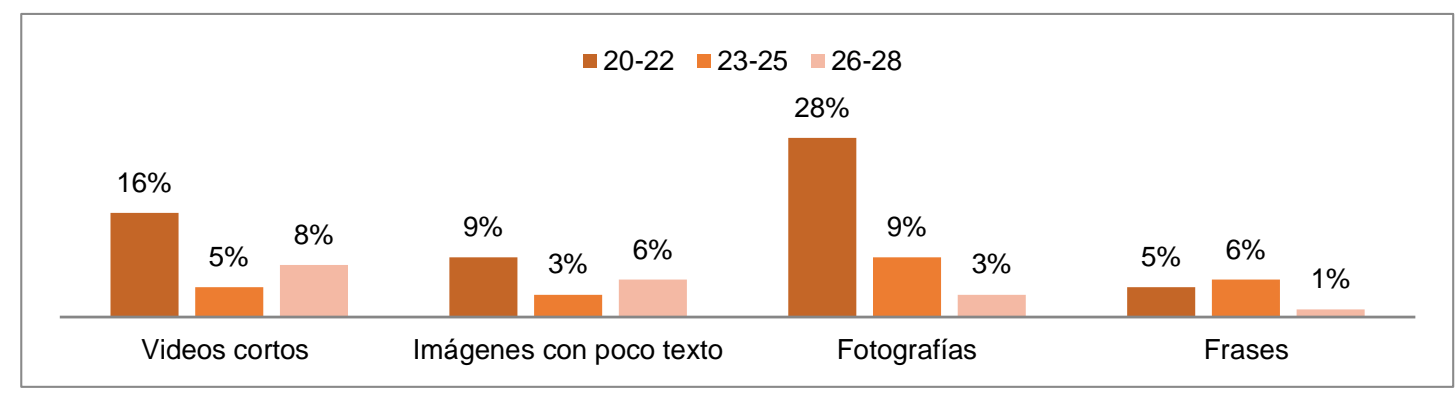

En cuanto a los artículos u objetos de mayor demanda, el $17 \%$ de las mujeres en su decisión de compra seleccionan ropa y calzados, el 15\% para artículos de belleza. Los estudiantes encuestados con el $16 \%$ optan por todo lo relacionado con el entretenimiento. Los factores para la decisión de compra, así como los medios en los que se pautan el contenido publicitario depende del target al cual se dirige, los resultados de la encuesta así lo evidencian, el público joven otorga un rol fundamental a las redes sociales tanto para informarse o seleccionar un producto.

\section{Figura 23}

Productos que prefieren comprar

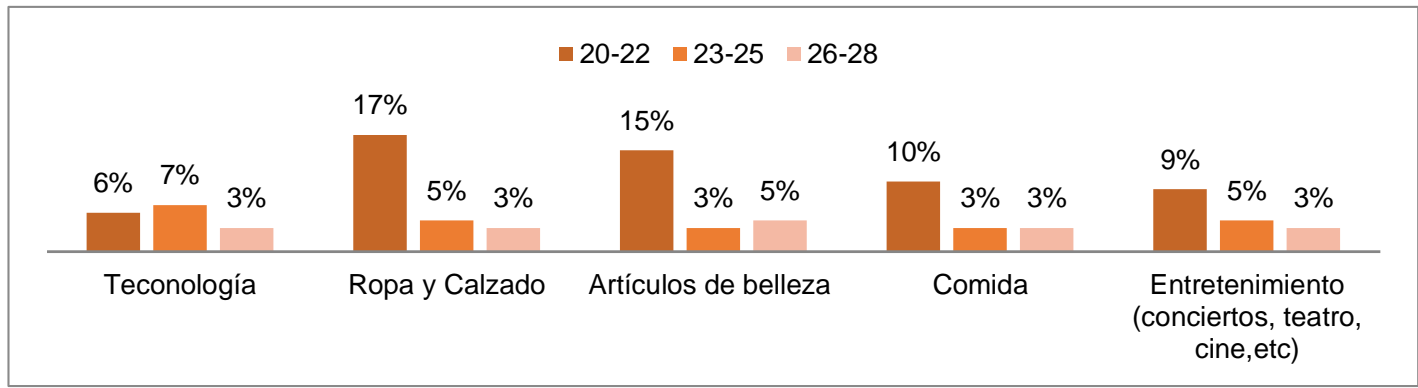

\section{Figura 24}

Productos que prefieren comprar

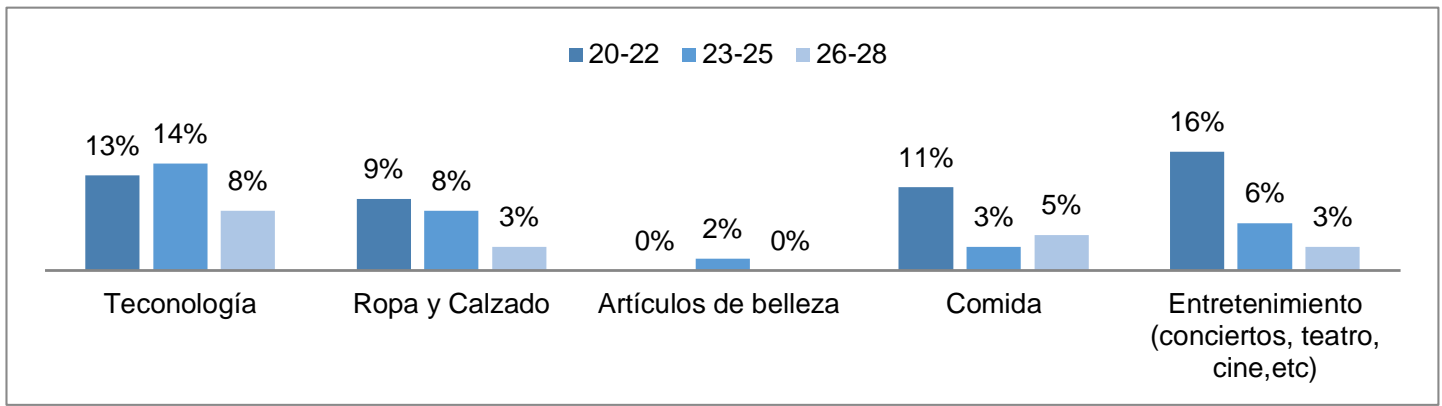


Con el fin de contrastar estos resultados se efectúan entrevistas a profesionales y docentes ${ }^{5}$ con experiencia en la temática abordada: comunicación publicitaria, estrategias, entre otras y cómo estás influyen a través de las redes sociales.

Las plataformas digitales y las redes sociales constituyen tendencias en el consumo y producción de información, para Moreira (2019, comunicación personal), en entrevista con las autoras es necesario apuntar a las nuevas tendencias de la publicidad, puesto que la intención de los grupos, empresas e instituciones que manejan marcas es que la audiencia se sienta identificada y que generen una posible acción, es decir producir empatía y afinidad.

En la actualidad, la publicidad genera contenidos, por ello es denominada Brandcontent 6 por cuanto contacta con la parte emocional del potencial comprador, en entrevista con las autoras Rodríguez (2019, comunicación personal), considera que el vínculo entre consumidor y marca se establece a través de la publicidad y el sentido de pertenencia e identificación, sobre todo en el sector juvenil, grupo que, según su consideración, no busca publicidades sino interacciones, por aquello indica que es importante generar comunidad en redes sociales.

La sinergia de estrategias en la red, aunado a medios tradicionales y otras técnicas comunicacionales generan una comunicación 360, en entrevista con las autoras Rivadeneira (2019, comunica) y Moreira (2019, comunicación personal) coinciden en que una marca debe recurrir a diversas estrategias para orientar la toma de decisión de compra. Para ello, el acercarse a sus diferentes grupos de interés, así como recurrir a otras técnicas comunicacionales como las Relaciones públicas (RRPP) y la misma Publicidad, crean un valor agregado.

Argumentar para influir en el comportamiento de consumo, implica comunicar atributos y beneficios, sin embargo, el componente ético, valido para cualquier profesión, en el caso específico de la publicidad es fundamental, esto permite potencializar a empresas o marcas (Rodríguez, 2019 en entrevista con las autoras).

Las marcas conectan a su público, para ello planifican el Mix de medios adecuado con el segmento pretendido, adaptándose a los cambios según las épocas y generaciones, de esta manera Facebook e Instagram presencian cambios estratégicos constantes Moreira (2019, comunicación personal) en entrevista con las autoras, al respecto toma como ejemplo a Market Place de Facebook, plataforma que oferta productos y servicios. Además, reflexiona sobre la importante aplicación de estrategias las cuales no deben quedarse estáticas sino adaptarse a los cambios de comportamientos del consumidor.

\footnotetext{
${ }^{5}$ Síntesis biográfica de los entrevistados: Ing. Juan Arturo Moreira García: Ingeniero en Gestión empresarial internacional de la Universidad Católica de Santiago de Guayaquil, Máster de la Universidad de Palermo en Dirección de Empresas, actualmente labora como catedrático de la UCSG en la carrera de Mercadotecnia.

Lcda. María Pía Rodríguez Cavaliere: Licenciada en Publicidad, Redactora Publicitaria del instituto de la Asociación Argentina de Publicidad, se desempeña como Gerente General de la Agencia de Publicidad Felino Argentina y Ecuador.

Lcda. Emilia Rivadeneira: Licenciada en Comunicación Organizacional y Relaciones Públicas de la Universidad San Francisco de Quito, Maestría en Gestión de Proyectos de la ESPAE. Actualmente labora como Relacionista Pública de LATAM ECUADOR.

${ }^{6}$ Branded Content: técnica de marketing que consiste en crear contenidos vinculados a una marca que permitan conectar a esa marca con el consumidor.
} 
Actualmente Instagram se ha convertido en una de las redes sociales con mayor cantidad de usuarios y en este espacio la publicidad ha desplegado su accionar con las diversas herramientas que desarrollan contenidos de marca. En entrevista con los autores Rivadeneira (2019, comunicación personal), asume que la red en mención tiene virtudes dirigidas hacia un sector juvenil y que prioriza lo audiovisual y la exposición del producto o servicio es más directa.

Lo digital reduce distancias y la creatividad, continúa siendo el eslabón, para la interacción y la bidireccionalidad de la comunicación. En entrevista con las autoras Rodríguez (2019, comunicación personal) y Rivadeneira (2019, comunicación personal) consideran que la creatividad es un punto clave, para que las empresas puedan desarrollar mensajes a partir de los intereses, gustos del usuario y maximizar resultados orientados a las decisiones de compra.

\section{Discusión}

Adolescentes y jóvenes son susceptibles de la manipulación mediática de los medios y nuevas plataformas de la WEB 2.0, el público objeto de estudio analizado se encuentra en una edad de 20 a 22 años, siendo el sexo femenino el mayoritario con relación al masculino. Ambos grupos evidencian un gran uso de las redes sociales, prefiriendo a la red social Instagram para información publicitaria. Sin embargo, resulta importante señalar que el uso de Facebook se encuentra presente.

Para los autores Marcelino (2015) y Rivadeneira (2019), la migración juvenil de Facebook hacia Instagram se debe a que dicha red cubre las necesidades que actualmente los jóvenes requieren, tales como herramientas más actualizadas que preponderan lo audiovisual con una apariencia inmediata del producto.

Conforme a la información proporcionada por las encuestas en ambos grupos poblacionales existe una posición a favor del contenido publicitario en redes, según Velasco (2013) y Rebollo-Bueno (2019), se crean espacios en donde la información y opinión generen una vocería ciudadana. Por su parte Rodríguez (2019) coincide en que la interacción forma parte esencial en la comunidad en redes.

Respecto a las redes sociales analizadas, Moreira (2019) a través de una entrevista coincide con el autor Ochoa \& Uribe (2015), sobre el hecho de que las marcas o empresas deben generar empatía y así el público estaría dispuesto a compartir, comprar o recomendar. Contactar implica crear un brandcontent, es decir marcas que liguen lo emocional e impliquen al usuario.

La ética en redes sociales cumple un rol importante, Pellicer (2015) concuerda con Rodríguez (2019) el público es el mayor crítico de cada uno de los perfiles, es aquí donde se presentan reclamos o felicitaciones, por ende, la credibilidad de la marca parte de la verdad del producto en función de los atributos y beneficios percibidos por el target. 
A medida que la tecnología y plataformas virtuales innovan, son evidentes los cambios de comportamiento del consumidor, es por esto por lo que Moreira (2019), Alonso (2017) y Ahmad Zareie, Amir Sheikhahmadi, Mahdi Jalilización (2020) destacan que las estrategias se adaptan según la conveniencia y objetivos en una campaña, por ejemplo, los personajes populares que representen una marca, según datos recolectados las estrategias que predominan son los Influencers y videos cortos.

El resultado de las encuestas y las entrevistas realizadas destacan la necesidad de comunicarse con los públicos de forma interactiva, la usabilidad de las plataformas digitales y las redes sociales apuntan a tendencias en el consumo y producción de información. Es fundamental contactar a los públicos y crear un engagement, mediante la generación de contenidos para contactar con la parte emocional del potencial comprador y establecer un vínculo que se tangibiliza con acciones como establecer el número de visitas al sitio, la actividad y presencia (me gusta, comentarios) en las redes sociales del anunciante.

El cambio de estrategias y el reacomodo en los medios tradicionales a las nuevas demandas de públicos que demandan participación, de acuerdo con los cambios según las épocas y generaciones implica asumir formas de comunicación cercanas y lúdicas para entretener al mismo tiempo que se realiza una compra, para fidelizar cuando se enamora con la marca mediante las emociones.

Los jóvenes recurren a las plataformas digitales, que es un espacio en constante evolución en este análisis se ha establecido factores de comportamiento de consumo más allá de las métricas que son datos importantes para el anunciante que establece la efectividad de la publicidad en una red social, por lo cual las estrategias publicitarias empleadas en una red social cumplen con objetivos empresariales, para Novoa (2019) contactar a los grupos objetivos, constituye un factor clave, para ello el empleo de estrategias digitales, tales como pautar anuncios en las historias desarrollada en Instagram es atrayente para un público femenino joven. Domínguez \& Jarvio (2015) concuerdan que las mujeres crean contenidos en sus historias para obtener vínculos sociales y familiares, en cambio los hombres se orientan al entretenimiento.

\section{Conclusiones}

Como consecuencia de lo expuesto se puede concluir que la influencia de la publicidad a través de redes sociales es notable en el sector más joven de acuerdo con los rangos de edades señalados en la investigación.

Las estrategias de comunicación y marketing se direccionan a los cambios en los gustos y preferencias del segmento de mercado pretendido y a sus nuevas demandas para lo cual el empleo de una las herramientas más importantes es la publicidad, que se torna fundamental.

Como se puede observar el comportamiento del consumidor es uno de los puntos clave para lograr una toma de decisión de compra favorable a los intereses de la empresa. En este sentido los estudiantes de la carrera de Comunicación Social priorizan la inmediatez y lo audiovisual como guía publicitaria para satisfacer sus necesidades. 
Los datos generados por los usuarios son de importancia para las empresas o marcas, que buscan contactarlos y crear una experiencia de marca, un Branded content y un engagement con el potencial consumidor quien necesita identificación e interacción.

En términos generales la época actual en que la tecnología y las nuevas formas de comunicación cambian de forma acelerada es necesario recurrir a otras formas de comunicación publicitaria distinta a la clásica (publicidad ATL) e instar por una publicidad más cerca (publicidad BTL y OTL) o mejor aún a una comunicación integral conociendo que el consumismo de los jóvenes es una característica que incide en la búsqueda de información de una manera instantánea y ese es el 1 reto que tendrán que asumir las empresas y marcas.

\section{Referencias bibliográficas}

Alonso-Gonzalez, A. (2017). Nuevas Tendencias del Marketing en las Ciencias Económicas y Administrativas. Cuadernos Latinoamericanos de Administración, XIII(25), 5-6.

Barbosa Chacón, J. W., Barbosa Herrera, J. C., \& Rodríguez Villabona, M. (2013). Documentary review and analysis for state-of-the-art assessment: A methodological proposal using educational experiences systematization approach. Investigación Bibliotecológica: archivonomía, bibliotecología e información, 27(61), 83-105.

Barrientos Felipa, P. (2017). Marketing + internet = e-commerce: oportunidades y desafíos. Revista finanzas y política económica, 9(1), 41-56.

Díaz-Bravo, L., Torruco-García, U., Martínez-Hernández, M., \& Varela-Ruiz , M. (2013). La entrevista, recurso flexible y dinámico. Investigación en Educación Médica, 2(7), 162167.

Domínguez Palmeros, H., Hernández Maldonado, M. L., \& Jarvio Fernández, A. O. (2015). Análisis estadístico de datos textuales aplicado al uso de redes sociales. CPU-e, Revista de Investigación Educativa(21), 1-27.

Fondevila-Gascón, J. -F., López, P., Rodríguez, R., \& Mir, P. (2020). Social Media Influence on Consumer Behavior: The Case of Mobile Telephony Manufacturers. Sustainability, 12.

Hernández Sampieri, R., Fernández Collado , C., \& Baptista Lucio, P. (2014). Metodología de la Investigación. Sexta Edición. México: McGRAW-HILL.

Himelboim, I., \& Golan, G. (2019). A Social Networks Approach to Viral Advertising: The Role of Primary, Contextual, and Low Influencers. Social Media + Society ., 5(3), 10.

La Voz. (23 de agosto de 2019). Facebook quiere llenar de publicidad las historias de Instagram (todavía más que ahora). Obtenido de La Voz:

https://www.lavoz.com.ar/tecnologia/facebook-quiere-llenar-de-publicidad-historias-deinstagram-todavia-mas-que-ahora

Marcelino Mercedes, G. V. (2015). Spanish youth and teenagers migrating through social networks. From Tuenti to Facebook and from Facebook to Instagram. The second migration. ICONO 14, Revista de comunicación y tecnologías emergentes, 13(2), 48-72.

Méndiz, A., Victoria, J., \& Arroyo, I. (2013). La Eficacia De La Publicidad Social En Las Redes Sociales. Un Experimento Online Con Usuarios Jóvene. Razón y Palabra(82), 1-20. 
Moreira García, J. A. (15 de Octubre de 2019). Análisis de la Influencia de la comunicación publicitaria a través de las redes sociales. (K. Ortega, Entrevistador) personal. Guayaquil.

Novoa Montoya, A. (2019). Publicidad dinámica y contextual. La revolución de las audiencias y el empoderamiento de medios, códigos y redes. La revista Pensar la Publicidad. Revista Internacional de Investigaciones Publicitarias, 13, 295-315.

Ochoa Gutiérrez, P. N., \& Uribe Alvarado, I. (2015). Sentido de la interacción social mediada por Facebook en un grupo de adolescentes, México. Estudios sobre las Culturas Contemporáneas, XXI(42), 9-37.

Otzen, T., \& Manterola, C. (2017). Técnicas de Muestreo sobre una Población a Estudio. International Journal of Morphology, 35(1), 227-232.

Pellicer Jordá, M. T. (2015). 5 REASON FOR AN ETHIC ADVERTISING. Revista de Comunicación de la SEECI.(38), 301-316.

Pimienta Lastra, R. (2000). Encuestas probabilísticas vs. no probabilísticas. Política y Cultura(13), 263-276.

Pole, K. (2009). Diseño de metodologías mixtas. Una revisión de las estrategias para combinar metodologías cuantitativas y cualitativas. Revista Renglones(60), 37-42.

Rebollo Bueno, S. (2019). "Social media", interacción y publicidad. Percepción de los formatos y contenidos en la Web 3.0. Pensar La Publicidad. Revista Internacional De Investigaciones Publicitarias, 13, 191-207.

Rivadeneira, E. (4 de septiembre de 2019). Análisis de la influencia de la comunicación publicitaria a través de las redes sociales. (K. Ortega, Entrevistador)

Rodrigues, A., Tavares, B., Silva, I., Brito, M., \& Au-Yong-Oliveira,, M. (2018). Social networks and internal corporate communication: Help or hindrance?, (pág. 659). Portugal.

Rodríguez Cavaliere, M. P. (20 de octubre de 2019). Análisis de la influencia de la comunicación publicitaria a través de las redes sociales. (K. Ortega , Entrevistador) personal. Guayaquil.

Rowles, D. (2018). Digital Branding. Bogotá: ECOE Ediciones.

Rubalcava de León, C. A., Sánchez-Tovar, Y., \& Sánchez-Limón, M. L. (2019). La conciencia de marca en redes sociales: impacto en la comunicación boca a boca. Estudios Gerenciales, 35(152), 313-320.

Serrano-Malebrán, J., \& Arenas-Gaitán, J. (2019). Anuncios comprables en redes sociales móviles: alta personalización y preocupación por la privacidad. GECONTEC: Revista Internacional De Gestión Del Conocimiento Y La Tecnología, 7(2), 66-79.

Tabellion, J., \& Esch, F.-R. (2019). Influencer Marketing and its Impact on the Advertised Brand. Advances in Advertising Research X, 29.

Turban, E., Outland, J., King, D., Lee, J., Liang, T.-P., \& Turban, D. (2017). Social Commerce: Foundations, Social Marketing, and Advertising. Electronic Commerce 2018, 285-324.

Vaca Torres, B., Carpio Jiménez, L., Barrazueta, P., \& Ordóñez, K. (2020). Los estereotipos y la representación de género en la publicidad ecuatoriana. Iberian Journal of Information Systems and Technologies(E26), 335 - 347.

Valerio Ureña, G., Herrera Murillo, D., Villanueva Puente, F., Herrera Murillo, N., \& Rodríguez, M. (2015). The Relationship between Post Formats and Digital Engagement: A Study of the Facebook Pages of Mexican Universities. RUSC. Universities and Knowledge Society Journal, 12(1), 50-63. 
van Rhyne, Z., Willie , C., \& Liezel, C. (2019). Social network addiction and advertising on social networks: A case study of rural students in South Africa. South African Journal of Information Management, 21(1), 4;5.

Velasco, M. (2013). Redes sociales, lo público y lo político en construcción. Centro Internacional de Estudios Superiores de Comunicación para América Latina(121), 8187.

Wiese, M., Martínez, C. C., \& Botella, D. C. (2020). A framework for Facebook advertising effectiveness: A behavioral perspective. Journal of Business Research, 109, 82-83.

Zareie, A., Sheikhahmadi, A., \& Jalilización , M. (2020). Identification of influential users in social network using gray wolf optimization algorithm. Expert Systems with Applications, 142. 